\title{
Vitamin C supplementation during chronic variable stress exposure modulates contractile functions of testicular artery and sperm parameters in male Wistar rats
}

\author{
Shakiru Ademola Salami ${ }^{1 *}$ (D, Hussein Mofomosara Salahdeen ${ }^{1}$, Oyinlola Toluwani Moronkola ${ }^{1}$, \\ Babatunde Adekunle Murtala ${ }^{1}$ and Yinusa Raji ${ }^{2}$
}

\begin{abstract}
Background: Humans are exposed to identifiable multiple environmental stressors. However, there is paucity of studies assessing chronic variable stress (CVS) exposure together with antioxidant supplementation on reproductive function. This study investigates impact of vitamin C supplementation, during CVS exposure on contractile functions of testicular artery and sperm parameters. Twenty pubertal male Wistar rats (150-200 g) were grouped into four of five rats each consisting of control (normal saline), vitamin C treated (7 mg/kg bwt), chronic variable stress (CVS) + vitamin C, and CVS only. Animals were treated respectively for 8 weeks. Serum superoxide dismutase (SOD), catalase, malondialdehyde (MDA) activity, testosterone, and cortisol were assayed. Contractile responses of excised testicular artery to phenylephrine, potassium chloride, acetylcholine, and sodium nitroprusside were determined using Ugo Basile data acquisition system. Sperm parameters and histopathology of the testis were also determined. Statistical significance was taken at $p<0.05$

Result: MDA activity was significantly increased in group exposed to chronic variable stress. However, groups supplemented with vitamin C during CVS exposure showed no significant increase. Serum SOD and catalase were enhanced in group exposed to CVS with vitamin C supplementation when compared to group exposed to chronic variable stress only. Chronic variable stress exposure increased serum cortisol level and this was attenuated with vitamin C supplementation. Vitamin C supplementation significantly increased serum testosterone level when compared to CVS only exposed group. Contraction responses of testicular arterial strips to phenylephrine and potassium chloride were attenuated in vitamin C supplemented groups when compared to CVS only exposed group. Vitamin C supplementation during CVS exposure also enhanced relaxation of testicular artery strip to sodium nitroprusside and acetylcholine. Sperm count and percentage motility were significantly reduced in CVS only exposed group when compared vitamin $C$ supplemented group. Sperms cells with abnormal morphology were also significantly increased in chronic variable stress only exposed group when compared to control and vitamin $C$ supplemented groups.
\end{abstract}

Conclusion: Chronic variable stress adversely impacts contractility of testicular artery, sperm parameters, cortisol, and testosterone level. Vitamin C supplementation modulated these by suppressing MDA and enhancing antioxidant enzyme activity.

Keywords: Testicular artery, Chronic variable stress, Vitamin C, Sperm parameters, Modulation

\footnotetext{
* Correspondence: piety1424@yahoo.com

'Department of Physiology, Lagos State University College of Medicine, Ikeja,

Lagos State, Nigeria

Full list of author information is available at the end of the article
} 


\section{Background}

Stress is a state of threatened homeostasis caused by intrinsic or extrinsic adverse forces (stressors) and is counteracted by an intricate repertoire of physiologic and behavioral responses aiming to maintain/reestablish the optimal body equilibrium [1]. Prolonged stress situation with high circulating level of cortisol is reported to upset homeostasis causing harm to organs, tissues, and vulnerability to diseases [2]. Continuous exposure to stress is known to impair testosterone production, sperm, and erectile functions [3]. Inhibition of testosterone biosynthetic enzyme activity by stress-induced increase in serum glucocorticoids is postulated to be responsible for impaired testosterone secretion [4].

Oxidative stress-induced generation of free radicals is associated with diseases like cancer, Alzheimer, and erectile dysfunction [5]. Oxidative stress has been reported to not only cause but also exacerbate erectile tissue impairment through the reaction of superoxide $\left(\mathrm{O}_{2}-\right)$ with nitric oxide (NO), inhibiting relaxation of the corpus cavernosa [6]. Normally, penile cavernous and arterial smooth muscles play key roles in the erectile processes [7]. Hormones and brain nervous impulses are known to guide special nerve cells in the penis to produce nitric oxide [7]. This nitric oxide then relaxes smooth muscles in penile erectile arteries and erectile bodies [7]. Experimental evidences have suggested that arterial insufficiency in penile arteries usually precedes structural and functional changes in erectile tissues leading to organic erectile dysfunction $[8,9]$. Testicular tissues are predisposed to activity of free radicals and oxidative stress. Asadi et al. [10] identified reasons for this to include high cell division rate, competition by cells for oxygen, and low oxygen pressure due to weakened vessels.

It is known that balance between reactive oxygen species (ROS) and antioxidant capacity is vital in the pathophysiology of disease state [11]. Well-known antioxidants include beta-carotene, lutein, resveratrol, vitamin $\mathrm{C}, \mathrm{E}$, lycopene, and phytonutrients [12]. Our bodies produce some antioxidants, although this can be inadequate especially in stressful situation [12]. An increase in oral intake of vitamin $C$ has been proposed to be potentially beneficial in reducing oxidative damage to tissues by chemical reduction of oxidant species [13]. McCabe et al. [14] reported that sustained release of high dose vitamin $\mathrm{C}$ reduced anxiety and mitigate increased blood pressure in response to stress. Individuals are exposed to variable stress daily due to identifiable multiple environmental stressors. Apart from adverse implication of chronic stress, its variability has also been postulated to also impact negatively on body's adaptive response [15]. Evidently [16, 17], there exists paucity of studies despite prevalence in nature investigating effects of combined stresses on male reproductive functions and the impact of vitamin $\mathrm{C}$ supplementation. This study investigated the effect of chronic variable stress exposure with vitamin $C$ supplementation on stress biomarkers, sperm characteristics, and in-vitro contractile responses of testicular artery in adult male Wistar rats.

\section{Methods}

\section{Animals}

Twenty healthy adult male Wistar rats weighing between 150 and $200 \mathrm{~g}$ and purchased from College of Health Sciences Ogbomosho, Oyo state, Nigeria were used. Animals were acclimatized for 3 weeks under conventional laboratory conditions (temperature 25-27 ${ }^{\circ} \mathrm{C}$, humidity of $70 \%$, and $12 \mathrm{~h}$ light and $12 \mathrm{~h}$ dark cycle) and allowed free access to standard diet and water ad libitum. Standard protocol on animal handling and care (according to the declaration of Helshinki) were strictly adhered to. Procedures adopted were also certified by the Lagos State University College of Medicine Animal House Committee.

\section{Chemical and drugs}

Vitamin $\mathrm{C}$ was purchased from Spring Valley Pharmaceuticals, China. Calcium chloride $\left(\mathrm{CaCl}_{2}\right)$, glucose, sodium chloride $(\mathrm{NaCl})$, potassium chloride $(\mathrm{KCl})$, sodium hydrogen bicarbonate $\left(\mathrm{NaHCO}_{3}\right)$, sodium nitroprusside (SNP), phenylephrine (PE), and acetylcholine (ACh) were purchased from Sigma Corporation, St. Louis, USA.

\section{Stress models procedure}

The rats were exposed to variable stress models according to the method of Mueller and Bale [18], with slight modification for predator exposure and noise. Six painless, non-habituating stress models which do not affect feeding were adopted. They include immobility by restraining animal in $50 \mathrm{ml}$ tube for 20 min during light cycle, multiple cage changes at interval of $20 \mathrm{~min}$ for $2 \mathrm{~h}$ during light/dark cycle, saturated beddings with water overnight causing sleep deprivation, predator exposure by placing a cat in the same cage as the rats with a wire mesh separation, foreign object exposure in cage overnight, and exposure to 100 decibels sound for $4 \mathrm{~h}$ during the light cycle.

\section{Experimental design and treatment}

Twenty pubertal male Wistar rats (150-200 g) were randomly divided into four groups of five rats each. Groups 1 and 2 were treated with normal saline (vehicle) and vitamin C $7 \mathrm{mg} / \mathrm{kg}$ bwt [19], respectively orally. Groups 3 and 4 were exposed to chronic variable stress with group 3 concurrently treated orally with vitamin $\mathrm{C}$ (7 mg/kg bwt). Treatments and stress exposure were for 8 weeks in all groups. All animals were weighed 
weekly using weighing scale (Highland Adam Equipment, UK).

\section{Serum sample collection}

Cardiac puncture technique was used (after injecting 30 $\mathrm{mg} / \mathrm{kg}$ phento barbital) [20] to collect a single, good quality volume of blood into a plain bottle from the animals using a $5 \mathrm{ml}$ syringe with needle. The blood was allowed to stand at room temperature for 15-30 $\mathrm{min}$. Thereafter, it was centrifuged using a cold centrifuge (Model SM112, Uniscope Laboratory Centrifuge, England) at $4000 \mathrm{rpm}$ for $15 \mathrm{~min}$. The resulting supernatant designated serum was carefully aspirated using a Pasteur pipette into a plain bottle and stored at $-4{ }^{\circ} \mathrm{C}$

\section{Preparation of the testicular artery strip}

The rats were anaesthetized $(30 \mathrm{mg} / \mathrm{kg}$ phento barbital), before they were sacrificed by cervical dislocation [20]. The testis was surgically removed en bloc with care. The testicular artery was removed from the testis and placed in a petri-dish containing physiological salt solution (PSS). The testicular artery was suspended in a $50 \mathrm{ml}$ chamber of the organ bath. These chambers contained PSS with the following composition $(\mathrm{m} / \mathrm{mol}): \mathrm{NaCl}$ (118.2), $\mathrm{CaCl}_{2}$ (1.6), $\mathrm{KCl}$ (4.7), $\mathrm{NaHCO}_{3}$ (15.0), $\mathrm{KH}_{2} \mathrm{PO}_{4}$ (1.2), $\mathrm{MgSO}_{4}$ (1.2), and glucose (11.5). The temperature of the organ bath was maintained at $37{ }^{\circ} \mathrm{C}$ and the solution was bubbled with a $95 \% \mathrm{O}_{2}+5 \% \mathrm{CO}_{2}$ gas mixture (pH 7.35-7.40). Each testicular artery strip was anchored with a stainless-steel hook to an electronic transducer (model 7004; Ugo-Basile Varese, Italy) connected to a data capsule model 17400 for recording isometric contractions [20].

\section{Dose response of testicular artery strip to phenylephrine} and potassium chloride

The testicular artery was allowed to stabilize in the physiological solution for $90 \mathrm{~min}$ during which it was stimulated three times at $30 \mathrm{~min}$ interval with $10^{-7} \mathrm{M}$ phenylephrine. Cumulative dose response of the testicular artery to phenylephrine $\left(10^{-9}-10^{-5} \mathrm{M}\right)$ and $10-60 \mathrm{mM}$ $\mathrm{KCl}$ were thereafter determined. Isometric contractions generated were recorded through the data capsule acquisition system.

\section{Dose response of testicular artery strip to acetylcholine and sodium nitroprusside}

The testicular artery was allowed to stabilize in the physiological solution for 90 min during which it was stimulated three times at $30 \mathrm{~min}$ interval with $10^{-7} \mathrm{M}$ phenylephrine. Cumulative dose response of testicular artery to acetylcholine $\left(10^{-9}-10^{-5} \mathrm{M}\right)$ was determined after pre-contraction with $10^{-7} \mathrm{M}$ phenylephrine and $60 \mathrm{mmol} \mathrm{KCl}$. The response was ensured to maintain stable level before addition of another dose. Cumulative dose response to sodium nitroprusside (SNP) $\left(10^{-9}-10^{-5} \mathrm{M}\right)$ was determined after pre-contracting the testicular artery with $10^{-7} \mathrm{M}$ of $\mathrm{PE}$ and $60 \mathrm{mmol}$ $\mathrm{KCl}$ respectively.

\section{Histological preparation of the testis}

Sections obtained after preparations were stained with hematoxylin and eosin stains following clearance in xylene and were subsequently dried at $35-40{ }^{\circ} \mathrm{C}$. Photomicrographs were then taken at 200 and 400 magnifications [21].

Determination of serum superoxide dismutase, catalase, and malondialdehyde activity

Superoxide activity was assayed using a randox kit (Sigma Chemicals Ltd., USA). Catalase activity was determined according to the method of Aebi [22]. Malondialdehyde (MDA) an index of lipid peroxidation was determined using the method as described by Uchiyama and Mihara [23].

Determination of serum cortisol, testosterone, and sperm parameter analysis

Serum cortisol and testosterone were estimated using enzyme-linked immunosorbent assay (ELISA) method. Cortisol ELISA kit (DRG, USA) and testosterone ELISA kit Monoblind Inc. Lake Forest, CA, USA were used following the manufacturer instruction. Epididymal sperm count, percentage sperm motility, and abnormal sperm morphology were determined as reported by Raji et al. [21].

\section{Statistical analysis}

Results were expressed as means \pm standard error of the mean (SEM). Statistical analysis was done using graph pad prism version 5.0. Data were analyzed using oneway analysis of variance (ANOVA), Newman keuls test was used as post hoc test, and $p$ values less than 0.05 were considered statistically significant.

\section{Result}

Effect of chronic variable stress exposure with vitamin C supplementation on contractile responses of the testicular artery strip to phenylephrine and potassium chloride

Contraction responses of testicular arterial strips to phenylephrine $(\mathrm{PE})$ and potassium chloride $(\mathrm{KCl})$ were attenuated in vitamin $\mathrm{C}$ supplemented groups when compared to control and variable stress only exposed groups (Figs. 1 and 2). 


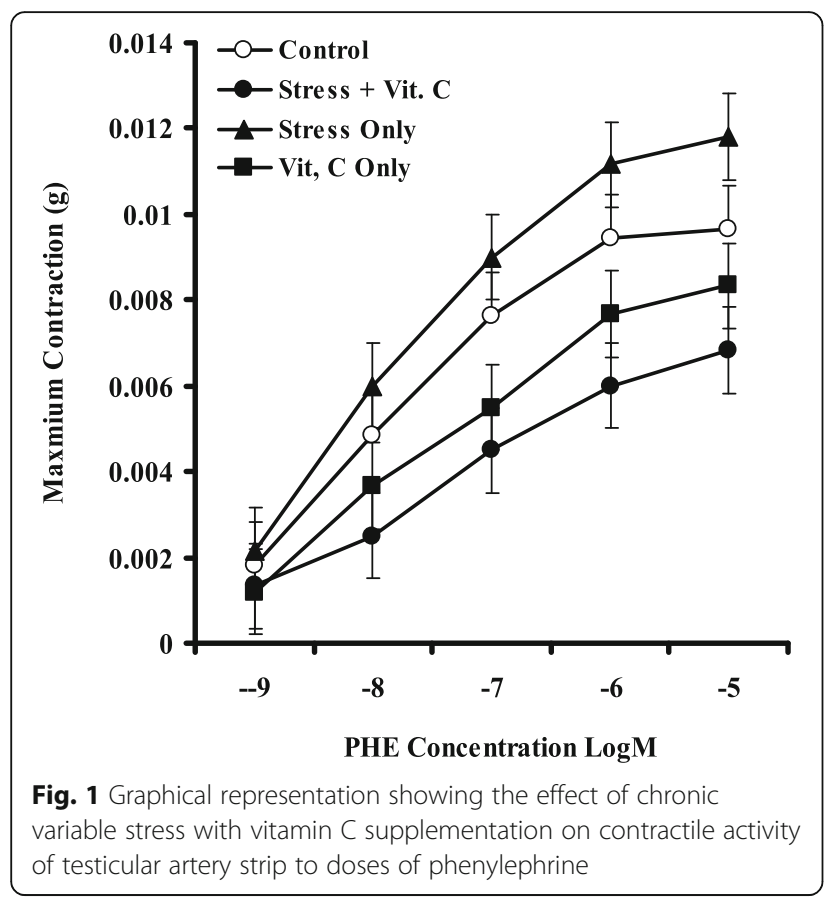

of testicular artery strip to doses of phenylephrine

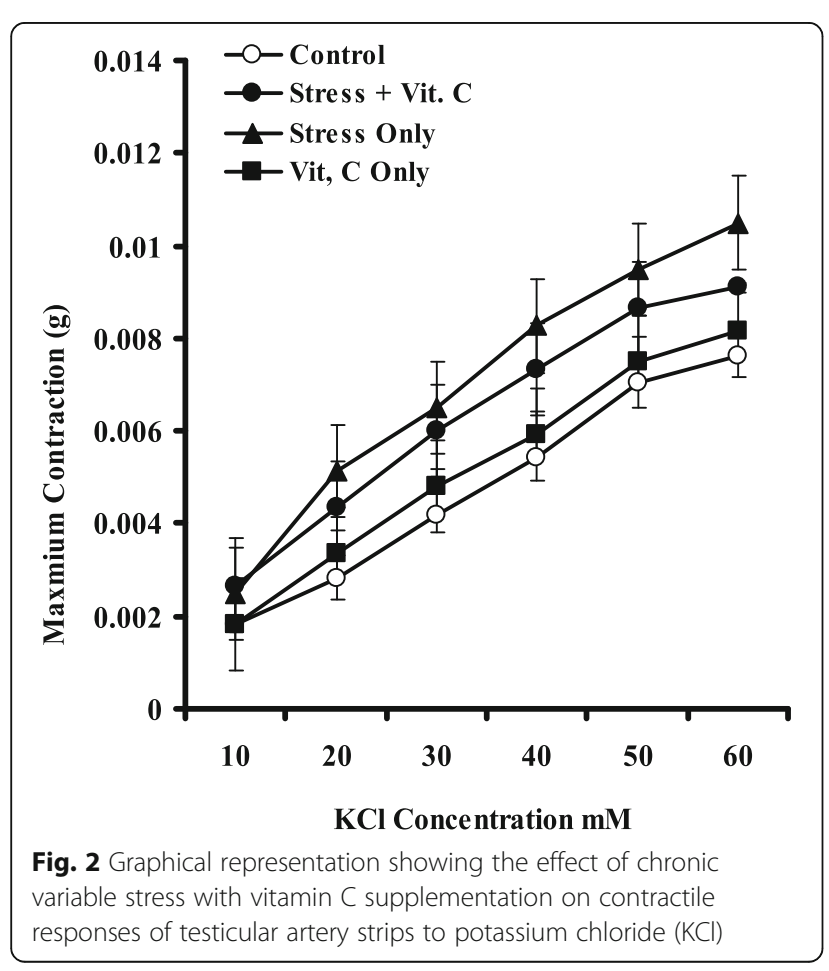

Effect of chronic variable stress exposure with vitamin C supplementation on relaxation responses of the testicular artery strips to sodium nitroprusside and acetylcholine Vitamin $C$ supplementation enhanced relaxation response of testicular arterial strips to SNP and acetylcholine (ACh) when compared to stress only group (Figs. 3 and 4).

Effect of chronic variable stress exposure with vitamin C supplementation on serum level of malondialdehyde activity, superoxide dismutase, and catalase Malondialdehyde activity was significantly increased $(p<$ 0.05 ) in group exposed to chronic variable stress only. However, groups supplemented with vitamin $C$ showed no significant increase (Fig. 5). Serum superoxide dismutase activity was enhanced in group exposed to chronic variable stress with vitamin $C$ supplementation when compared to group exposed to chronic variable stress only (Fig. 6). Catalase serum activity was significantly reduced $(p<0.0001)$ in group exposed to chronic variable stress. These reductions were attenuated with vitamin $C$ supplementation, though not significantly (Fig. 7).

\section{Effect of chronic variable stress with vitamin C}

supplementation on serum level of cortisol and testosterone Supplementation with vitamin $\mathrm{C}$ attenuated cortisol increase (Fig. 8). Vitamin $C$ supplementation with or without chronic variable stress exposure significantly increased serum testosterone level when compared to control and chronic variable stress only exposed group (Fig. 9).

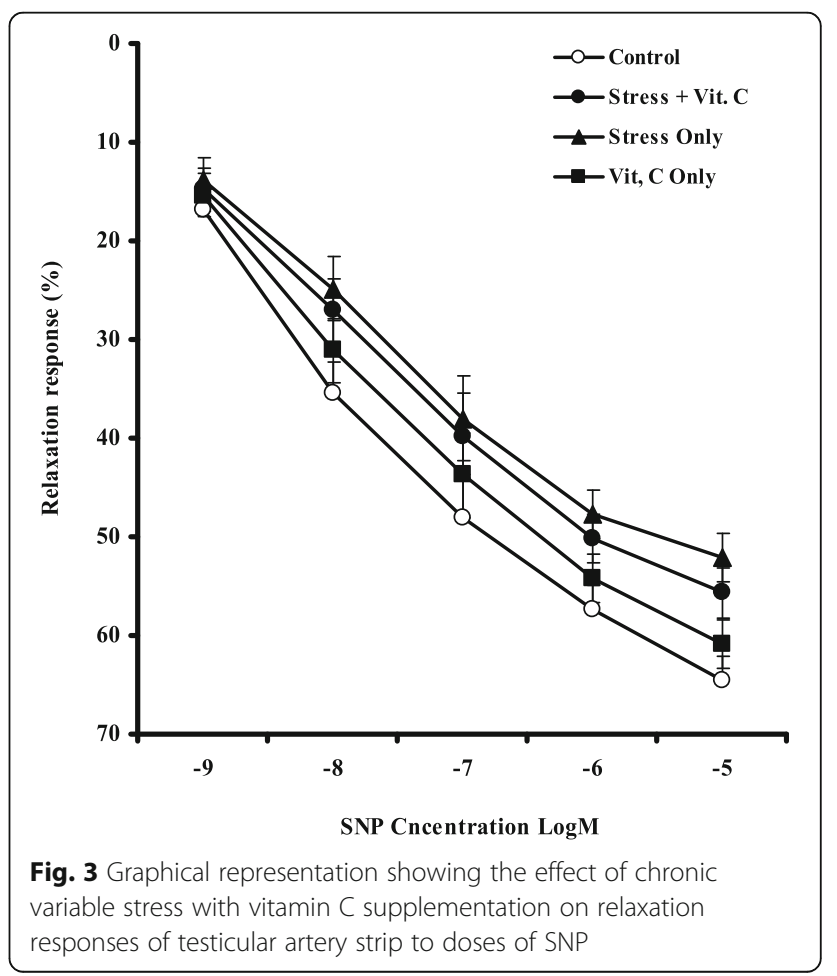




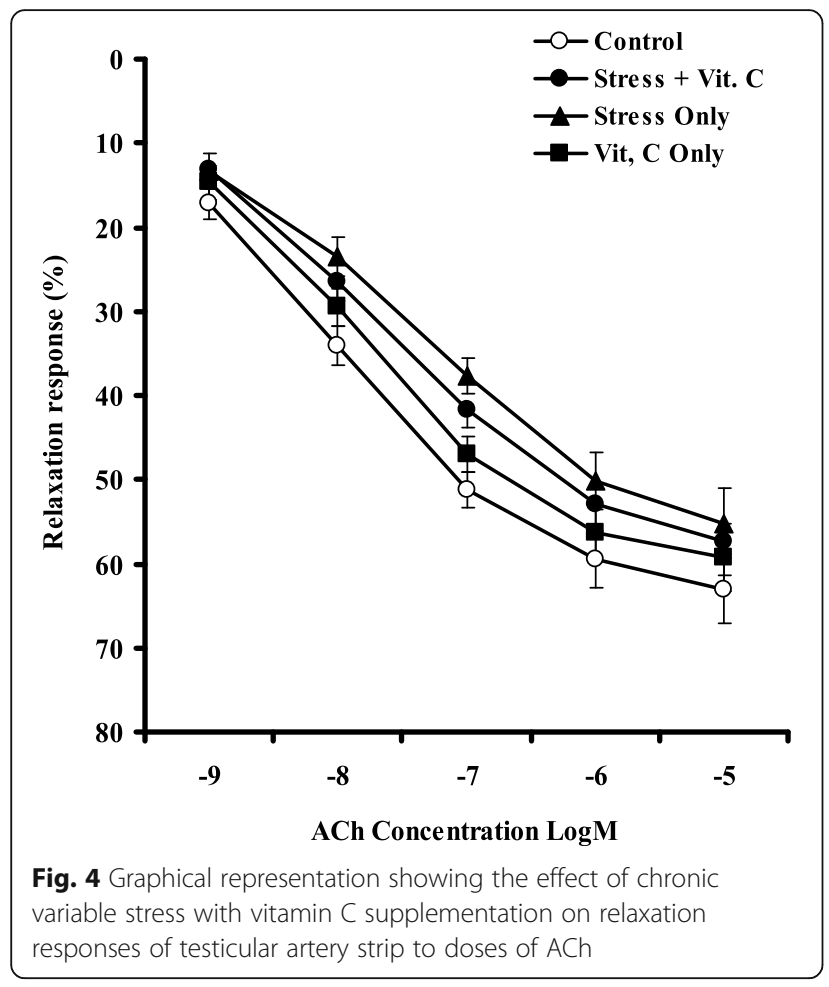

Effect of chronic variable stress with vitamin C supplementation on average final body weights of animals

At sixth week, average body weight in chronic variable stress only exposed group was reduced significantly (157 g) when compared to control $(242 \mathrm{~g})$ and groups supplemented with vitamin C with (246 g) or without $(264 \mathrm{~g})$ chronic variable stress exposure (Table 1$)$.

\section{Effect of chronic variable stress with vitamin C supplementation on sperm parameters}

Sperm counts and percentage sperm motility were significantly reduced in chronic variable stress only exposed group. Vitamin C supplemented groups however showed significant increase $(p<0.05)$ (Table 2). Percentage of sperm with abnormal morphology was significantly increased in chronic variable stress only exposed group while vitamin $C$ supplemented groups showed significant reduction (Table 2). Histological screenings showed no visible lesions in testis across all groups (Fig. 10).

\section{Discussion}

Contractile responses of testicular artery

The result from this study showed the in-vitro modulator capability of vitamin $C$ supplementation despite chronic variable stress exposure. As shown in this study, contraction responses of testicular arterial strips to $\mathrm{PE}$ and $\mathrm{KCl}$ were attenuated in vitamin $\mathrm{C}$ supplemented groups when compared to variable stress only exposed group. Vitamin C supplementation also enhanced relaxation of testicular artery strip to SNP and ACh when compared to stress only exposed group. $\mathrm{PE}$ and $\mathrm{KCl}$ are vasoconstrictors whose mechanism involves calcium release from intracellular stores through inositol triphosphate (IP3) production and calcium influx through L-type calcium channels respectively [24]. Oxidative stress resulting in ROS generation has been implicated in the impairment of complex intracellular endothelial and neuronal $\mathrm{NO}$ mechanism.

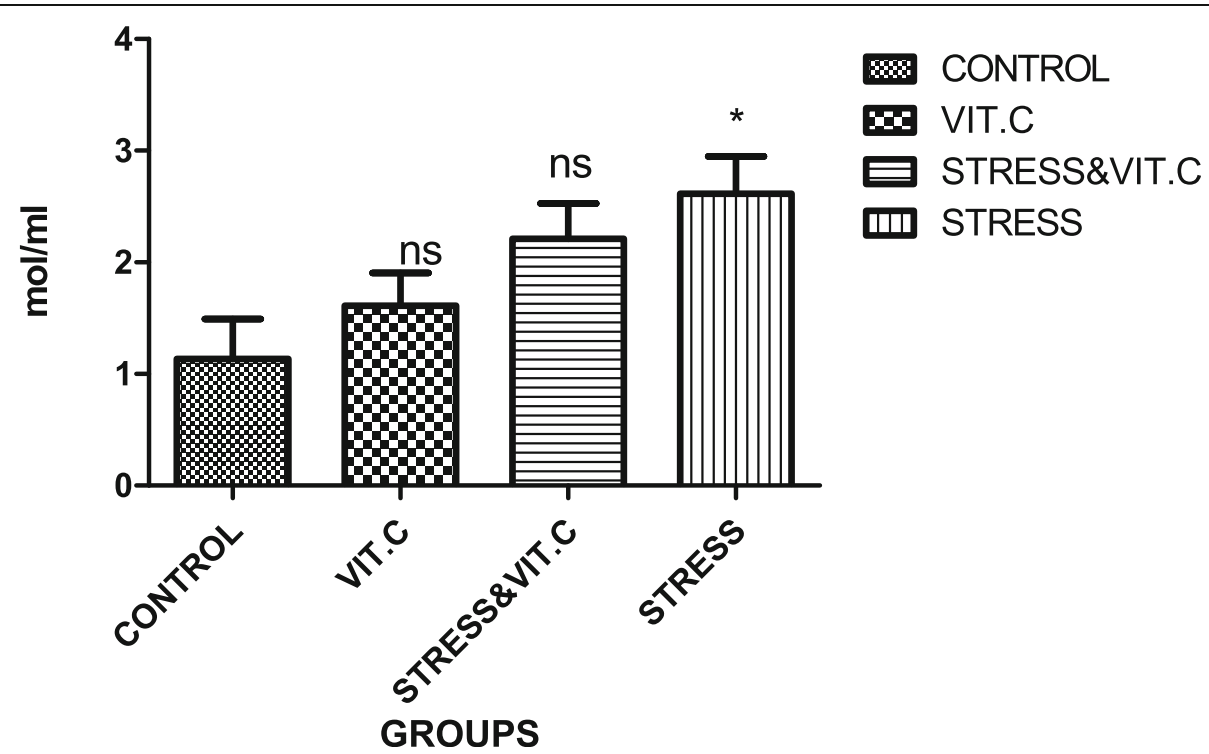

Fig. 5 Effect of chronic variable stress with vitamin C supplementation on serum malondialdehyde activity in Wistar rats. ${ }^{*} p<0.05$ when compared to control, ns no significance 


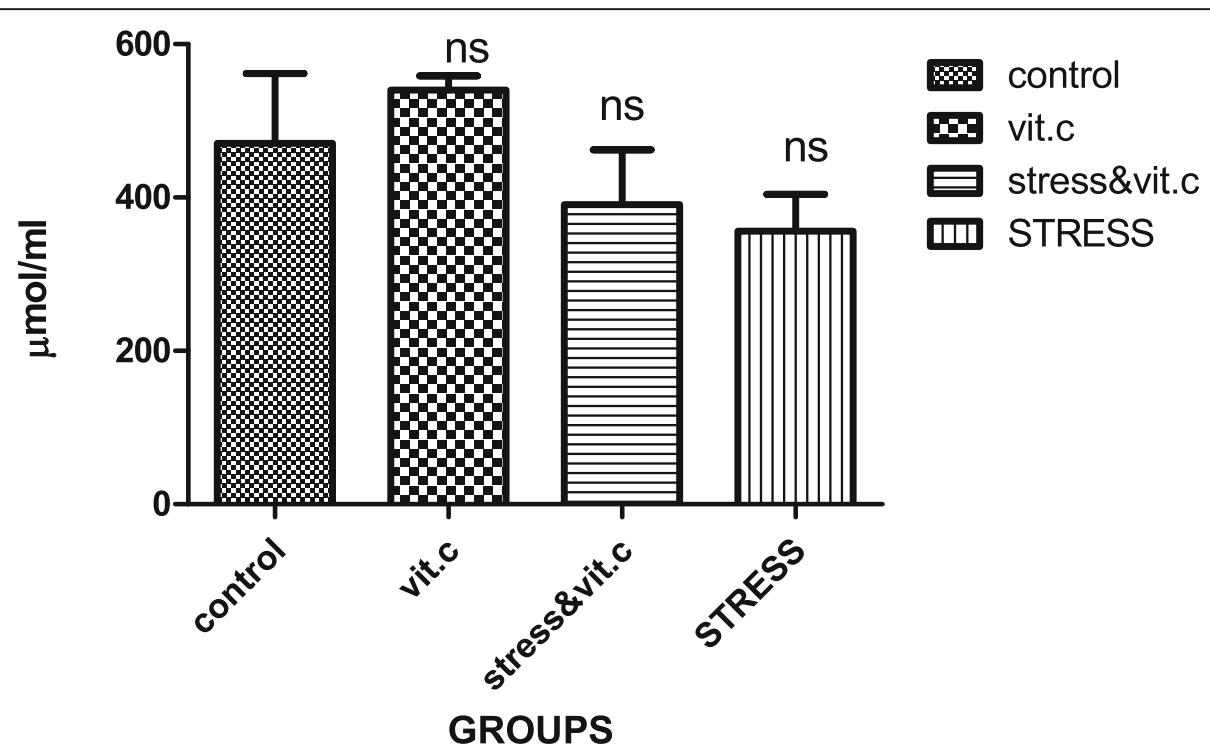

Fig. 6 Effect of chronic variable stress with vitamin C supplementation on serum level of superoxide dismutase in Wistar rat. ns no significance

Vitamin C supplementation in this study appear to counteract excessive damage to complex intracellular mechanism associated with stress-induced generation of ROS. The actual intracellular mechanism through which vitamin $C$ treatment was able to suppress this activity is currently unclear.

\section{Oxidative biomarkers activity}

In this study, MDA activity was significantly increased in group exposed to chronic variable stress only when compared to control. However, groups supplemented with vitamin $\mathrm{C}$ during chronic variable stress exposure showed no significant increase in MDA. Karafakioğlu [25] reported increased levels of MDA in noise only model of stress exposure with lipoic antioxidant supplementation reducing the MDA activity. Similarly, oxidative stress induced by hypoxia in animals was reported to significantly increase MDA activity with selenium supplementation significantly decreasing MDA tissue and plasma activity [26]. It is noteworthy that despite the variability in stress model adopted in this study as compared to these previous studies, vitamin $\mathrm{C}$

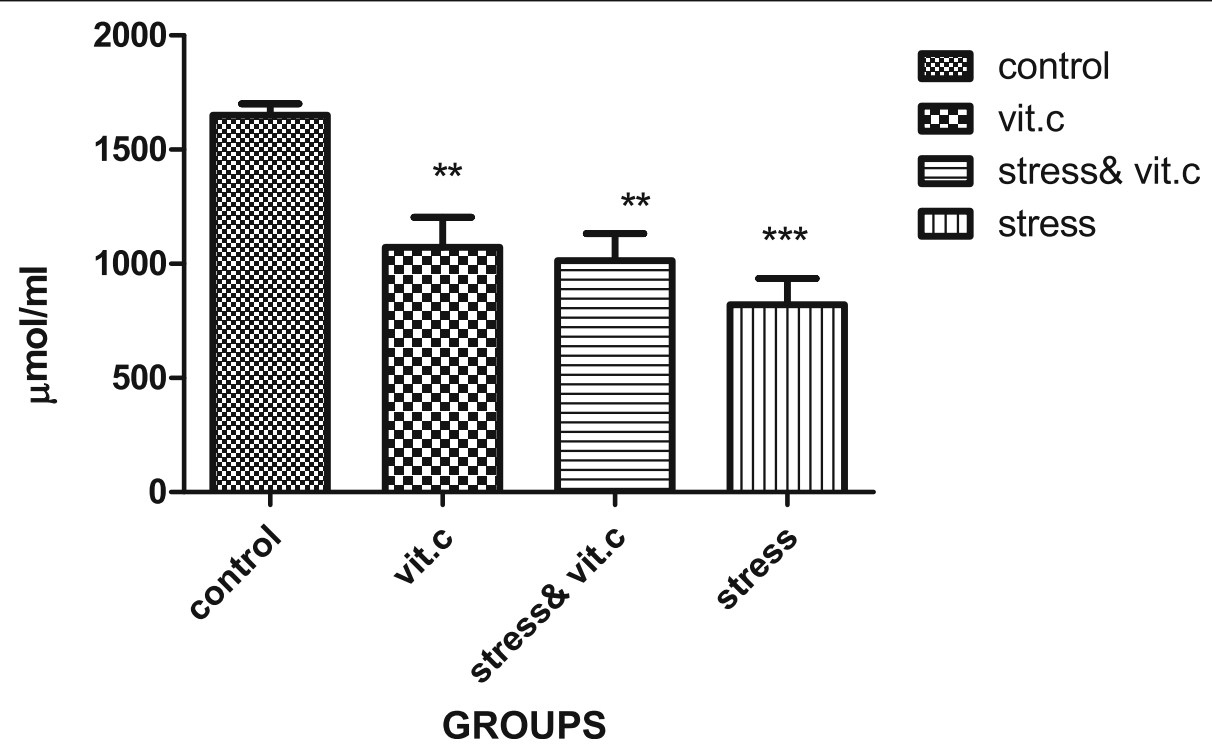

Fig. 7 Effect of chronic variable stress with vitamin C supplementation on serum level of catalase in Wistar rats. ${ }^{* *} p<0.001 ;{ }^{* *} p<0.0001$ when compared to control 


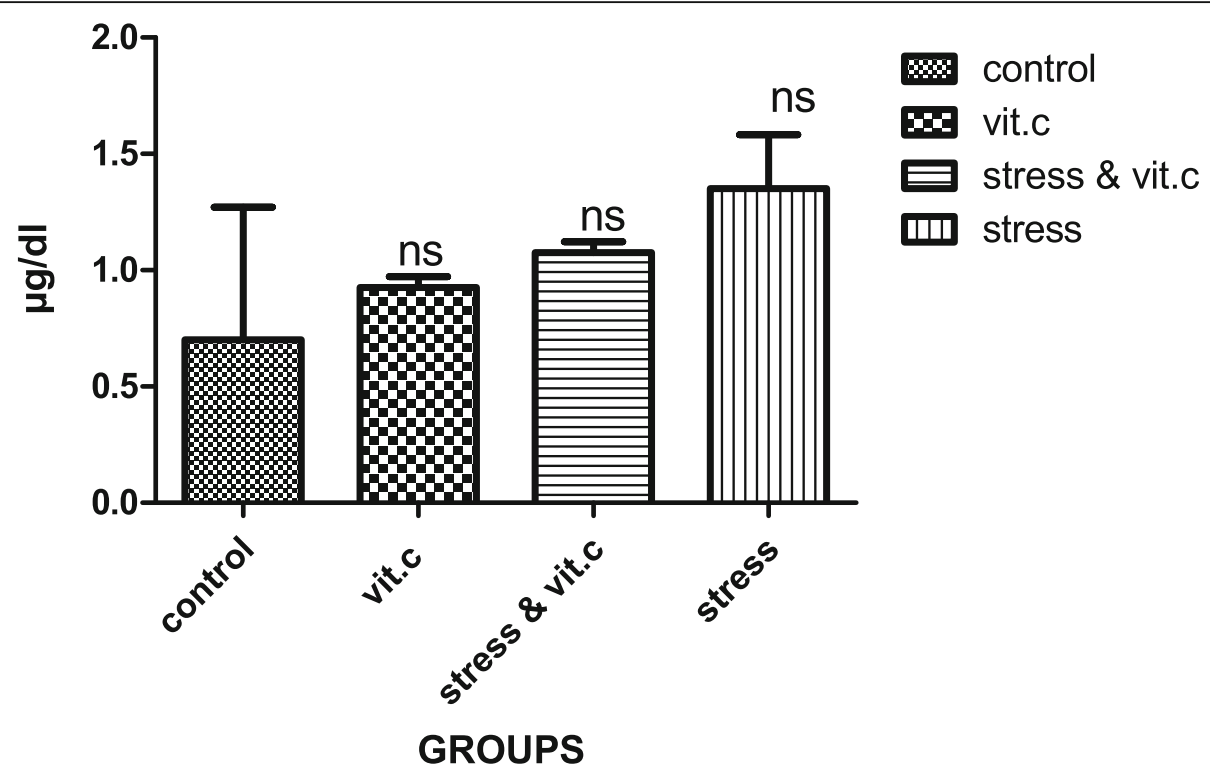

Fig. 8 Effect of chronic variable stress with vitamin C supplementation on serum level of cortisol hormone in Wistar rats. ns no significance

supplementation was able to suppress MDA activity. Bashandy et al. [27] had reported that increase in ascorbic acid concentration after supplementation is often sufficient to deal with increased free radical production and MDA formation. Though the plasma ascorbate concentration was not determined in this study, ascorbate anion of vitamin $C$ is reported to be the predominant form existing at physiological pH in the blood [28]. The most striking chemical activity of ascorbic acid as reported is its ability to act as a reducing agent, implicated in detoxifying various oxygen radicals invivo [28]. This activity is well exemplified as observed by the suppressed MDA activity of vitamin $C$ supplemented groups in this study.

Serum superoxide dismutase and catalase levels were enhanced in groups supplemented with vitamin $C$ when compared to group exposed to chronic variable stress only. The enhanced superoxide dismutase (SOD) and catalase activity was however not significant. It is currently unknown if increase in vitamin $\mathrm{C}$ dose might

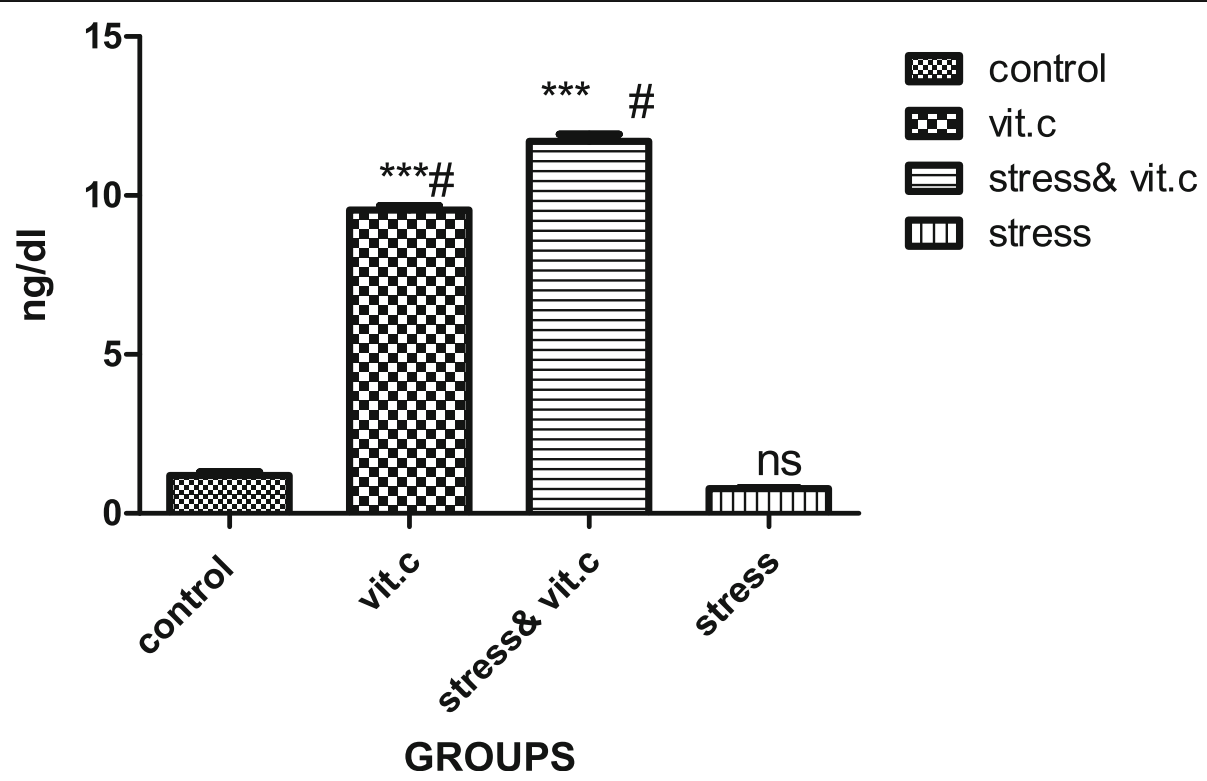

Fig. 9 Effect of chronic variable stress with vitamin C supplementation on serum level of testosterone hormone in Wistar rats. ${ }^{* *} p<0.0001$, \# significant when compared to stress only group, ns no significance 
Table 1 Effect of chronic variable stress exposure with vitamin C supplementation on average final body weight

\begin{tabular}{ll}
\hline Groups & Body weight (g) \\
\hline Control & $242 \pm 2.8$ \\
Vitamin C & $264 \pm 7.6$ \\
Stress + Vitamin C & $246 \pm 4.4$ \\
Stress & $157 \pm 3.4^{* \#}$ \\
\hline
\end{tabular}

${ }^{*} p<0.05$ when compared to control, $\# p<0.05$ when compared to vitamin $C$ supplemented groups

significantly enhanced their activity in CVS exposed group. Kashif et al. [29] had previously reported that pre and post stress treatment of rats with vitamin $C$ helped increase endogenous SOD and catalase level. SOD is an important endogenous first-line antioxidant enzyme against ROS [30]. It acts by catalyzing dismutation of two molecules of superoxide anion to less hazardous hydrogen peroxide and molecular oxygen. Catalase using either iron or manganese co-factor catalyzes the reduction of hydrogen peroxide $\left(\mathrm{H}_{2} \mathrm{O}_{2}\right)$ to water and molecular oxygen in order to complete the detoxification process initiated by SOD [30].

\section{Cortisol and testosterone activity}

Supplementation with vitamin $\mathrm{C}$ attenuated cortisol increase in this study while it increase $(p<0.05)$ testosterone level. Acute resistant stress [31], acute and chronic sleep-deprived rats [32] had been reported to cause elevated cortisol levels. The increase in cortisol was attributed to hypothalamic-pituitary-adrenocortical (HPA) axis feedback activation [31]. This feedback mechanism is known to be important for stress survival [31]. Although these aforementioned studies were on single stressor model, the slight attenuation in the cortisol levels in group supplemented with vitamin $C$ in this study highlight the modulatory potential of vitamin $\mathrm{C}$ during chronic variable stress exposure. Olayaki et al. [32] had earlier reported the ability of vitamin $\mathrm{C}$ causing significant decrease in cortisol levels of acute and chronic sleep-deprived stressed rats. Effect of stress on testosterone secretion in literature appears controversial with immobilization stress often reported to cause testosterone suppression [33, 34]. The result from this study shows that if stress application is varied and chronic, testosterone secretion is suppressed. This suppression appeared to be effected by elevated cortisols as observed in this study. Orr and Mann [35] had suggested that restraint stress causing increase in plasma glucocorticoids level act via glucocorticoid receptor in testicular interstitial cells to suppress the testicular response to gonadotrophin. Vitamin $\mathrm{C}$ supplementation of chronic variable stress exposure in this study however enhanced testosterone secretion; a similar elevation is reported by Damegh [34] though in immobilized stressed rats.

\section{Body weight and sperm parameters}

At sixth week, average body weight in chronic variable stress only exposed group was reduced $(157 \mathrm{~g})$ when compared to control (242 g) and groups supplemented with vitamin $\mathrm{C}$ with (246 g) or without (264 g) chronic variable stress exposure. Jeong et al. [36] also reported lower body weight and reduced food intake in restrained stressed against normal rats. Restraint stress was reported to reduce body weight and food intake by modifying food intake and energy metabolism related genes. The genetic modifications were suggested to be mediated partly by corticosterone. What is pertinent from our present study however is that, supplementation with vitamin $C$ reduced weight loss in chronic variable stress exposed group. In future, specific influence/role of vitamin $C$ on food intake and energy metabolism-related genes is worthy of being investigated.

In this study, epididymal sperm count and percentage sperm motility were significantly reduced in chronic variable stress only exposed group while vitamin $C$ supplementation caused a significant reversal. Percentage of sperm with abnormal morphology was also significantly reduced in vitamin $\mathrm{C}$ supplemented groups. Reactive oxygen species are involved in the impairment of sperm functions and their elevation plays major role in the etiology of defective sperm functions. Vitamin $\mathrm{C}$ supplementation in this study ameliorates defective effect of chronic variable stress on the semen quality. Vitamin $\mathrm{C}$ has been reported to protect sperm cells from oxidative stress induced loss of motility and deoxyribonucleic acid (DNA) damage [37, 38]. Corresponding data of suppressed MDA activity in vitamin $C$ supplemented group as reported in this study corroborates this finding.

Table 2 Table showing the effect of chronic variable stress with vitamin C supplementation on sperm parameters

\begin{tabular}{lllll}
\hline Parameters & Control & Vitamin C & Stress + Vitamin C & Stress \\
\hline Sperm count $\left(\times 10^{6} \mathrm{ml}\right)$ & $49 \pm 0.0$ & $89 \pm 3.5^{* * *}$ & $43 \pm 5.0$ & $19 \pm 2.0^{* *}$ \\
Abnormal sperm morphology (\%) & $19 \pm 2.0$ & $21 \pm 2.5$ & $30 \pm 2.5$ & $44 \pm 3.5^{*}$ \\
Sperm motility (\%) & $70 \pm 10$ & $60 \pm 10$ & $62 \pm 5.0$ & $18 \pm 2.5^{*}$ \\
\hline
\end{tabular}

${ }^{*} p<0.05 ;{ }^{* *} p<0.001 ;{ }^{* * *} p<0.0001$ 


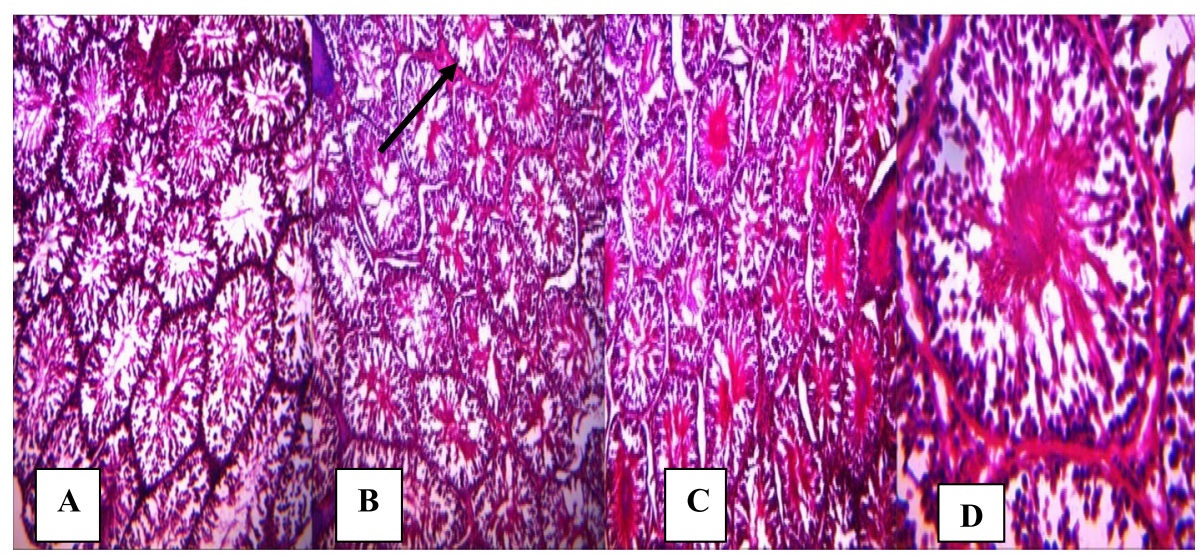

Fig. 10 Figures A-D: Photomicrographs showing effect of chronic variable stress exposure with vitamin C supplementation on histopathology of the testis (H \& E stain) A: Control(X200): no visible lesions, B: vitamin C treated (X200): no visible lesions but mild congestion of the interstitium, C: chronic variable stress (X200): no visible lesions, D: chronic variable stress+Vit C (X400): no visible lesions

\section{Conclusion}

Vitamin C supplementation substantially modulates reproductive risks in sperm characteristics and contractile functions of testicular artery after multiple chronic stressors exposure. Evidence from this study suggests scavenging power of vitamin $\mathrm{C}$ against destructive actions of ROS. Future studies should identify role of specific stress gene expression in this modulation.

\section{Abbreviations}

ACh: Acetylcholine; ANOVA: Analysis of variance; DNA: Deoxyribonucleic acid; ELISA: Enzyme-linked immunoabsorbent assay; NO: Nitric oxide:

PE: Phenylephrine; ROS: Reactive oxygen species; SNP: Sodium nitroprusside

\section{Acknowledgments}

Authors' acknowledged the contributions of Mr Oyetola, Department of Anatomy, Lagos State University College of Medicine, Ikeja and Dr Aina, Department of Veterinary Anatomy, University of Ibadan for the slides preparation and photomicrograph reading.

\section{Authors' contributions}

SA conceived, designed, supervised the study, and prepared the manuscript. HM designed the in-vitro protocol, supervised study, and read the manuscript. OT involved in data collection and part preparation of statistics. BA carried out the invitro technique and sample collections. Y mentoring and contributing to contents of the manuscript. All authors have read and approved the manuscript.

\section{Funding}

Authors' declare that funding was not from any specific donor source. Study was carried out through Institutional collaboration.

\section{Availability of data and materials}

All data are completely included within the manuscript. No data shared.

\section{Ethics approval and consent to participate}

Animal handling and experimentation was according to $\mathrm{NIH}$ guideline on use and care for laboratory animal. Reference number for ethical approval is CM/AEC/2019/02.

\section{Consent for publication}

All authors' read and approved the final draft of the manuscript. Authors' declare their consent for publication.

\section{Competing interests}

The authors declare that they have no competing interests.

\section{Author details}

'Department of Physiology, Lagos State University College of Medicine, Ikeja, Lagos State, Nigeria. ${ }^{2}$ Department of Physiology, University of Ibadan, Ibadan, Nigeria.

Received: 5 November 2019 Accepted: 27 January 2020

Published online: 19 February 2020

\section{References}

1. Tsigos C, Kyrou I, Kassi E, (2016) Stress, Endocrine physiology and pathophysiology. [Updated 2016 Mar 10]. In: Feingold KR, Anawalt B, Boyce A, et al., editors. Endotext. South Dartmouth: MDText.com, Inc; 2000-. Available from: https://www.ncbi.nlm.nih.gov/books/NBK278995

2. Mariotti A (2015) The effects of chronic stress on health: new insights into the molecular mechanisms of brain-body communication. Future Sci OA. https://doi.org/10.4155/fso.15.21

3. Wingfield JC, Sapolski RM (2003) Reproduction and resistance to stress: when and how. J Neuroendocrinol 8:711-724

4. Phaniendra A, Jestadi DB, Periyasamy L (2015) Free radicals: properties, sources, targets, and their implication in various diseases. Indian J Clin Biochem. 30:11-26. https://doi.org/10.1007/s12291-014-0446-0

5. Huang Y-C, Chin C-C, Chen C-S, Shindel AW, Ho D-R, Lin C-S et al (2015) Chronic cigarette smoking impairs erectile function through increased oxidative stress and apoptosis, decreased nNOS, endothelial and smooth muscle contents in a rat model. PLoS ONE 10(10):e0140728. https://doi.org/ 10.1371/journal.pone.0140728

6. Hu GX, Lian QQ, Lin H, Latif SA, Morris DJ, Hardy MP, Ge RS (2008) Rapid mechanisms of glucocorticoid signaling in the Leydig cell. Steroids. https://doi.org/10.1016/j.steroids.2007.12.020

7. Dean RC, Lue TF (2005) Physiology of penile erection and pathophysiology of erectile dysfunction. Urol Clin North Am. https://doi.org/10.1016/j.ucl. 2005.08.007

8. Prieto D (2008) Physiological regulation of penile arteries and veins. Int J of Impo Res 20:17-29

9. Carneiro FS, Webb RC, Tostes RC (2010) Emerging role for TNF-a in erectile dysfunction. J Sex Med. 7:3823-3834. https://doi.org/10.1111/j.1743-6109. 2010.01762

10. Asadi N, Bahmani M, Kharadmand A, Rafie-Kopaci M (2017) The impact of oxidative stress on testicular functionand the role of antioxidants in improving it. J Clin Diagn Res. 11:IE01-IE05

11. Sikka SC (2001) Relative impact of oxidative stress on male reproductive function. Curr Med Chem. 8:851-862

12. Kurutas EB (2016) The importance of antioxidants which play the role in cellular response against oxidative/nitrosative stress: current state. Nutr J. 15:71-76

13. Khassaf M, McArdle A, Esanu C, Vasilaki A, McArdle F, Griffiths RD, Jackson MJ (2003) Effect of vitamin C supplements on antioxidant defence and 
stress proteins in human lymphocytes and skeletal muscle. J Physiol 549(Pt 2):645-652. https://doi.org/10.1113/jphysiol.2003.040303

14. McCabe D, Lisy K, Lockwood C, Colbeck M (2017) The impact of essential fatty acid, B vitamins, vitamin C, magnesium and zinc supplementation on stress levels in women: a systematic review. JBI Database System Rev Implement Rep 2:402-453. https://doi.org/10.11124/JBISRIR-2016-002965

15. Lívea DG, Matheus TR, Polianna DP, Norberto GC, Eduardo HLU (2018) A Comprehensive overview on stress neurobiology: basic concepts and clinical implications. Front Behav Neurosci 12:1-23. https://doi.org/10.3389/ fn-beh2018.00127

16. Tipton MJ (2012) A case for combined environmental stressor studies. Extrem Physiol Med 1:7

17. Tipton MJ (2016) Environmental extremes: origin, consequences and amelioration in humans Exp. Physiol 101:1-14

18. Mueller BR, Bale TL (2006) Impact of prenatal stress on long term body weight is dependent on timing and maternal sensitivity. Physiol Behav 88:605-614

19. McEvoy CT, Schilling D, Clay N, Jackson K, Go MD, Spitale P et al (2014) Vitamin $C$ supplementation for pregnant smoking women and pulmonary function in their newborn infants. JAMA 311:2074-2082

20. Salami SA, Salahdeen HM, Ugbebor EC, Murtala BA, Raji Y (2018) Effects of aqueous leaf extract of Tridax procumbens on contractile activity of corpus cavernosum in N-nitro-L-arginine methyl ester-induced hypertensive male rats. J Integr Med 16:51-56

21. Raji Y, Fadare OO, Adisa RA, Salami SA (2006) Comprehensive assessment of the effect of Sphenocentrum jollyanum root extract on male reproductive activity in albino rats. Reprod Med Biol 5:283-292

22. Aebi H (1984) Catalase in vitro. Methods Enzymol 105:121-126

23. Uchiyama M, Mihara M (1978) Determination of malonaldehyde precursor in tissues by thiobarbituric acid test. Analytical Biochem 86:271-278

24. Zamponi GW, Striessnig J, Koschak A, Dolphin AC (2015) The physiology, pathology, and pharmacology of voltage-gated calcium channels and their future therapeutic potential. Pharmacol Rev. 67:821-870. https://doi.org/10. 1124/pr.114.009654

25. Karafakioğlu YS (2019) Effects of a lipoic acid on noise induced oxidative stress in rats. Saudi J Biol Sci. 26:989-994. https://doi.org/10.1016/j.sjbs.2018. 08.008

26. Sarada SK, Sairam M, Dipti P, Anju B, Pauline T, Kain AK, Sharma SK, Bagawat S, llavazhagan G, Kumar D (2002) Role of selenium in reducing hypoxia-induced oxidative stress: an in vivo study. Biomed Pharmacother 56:173-178

27. Bashandy S, Ebaid H, Abdelmottaleb Moussa SA, Alhazza IM, Hassan I, Alaamer A, Al Tamimi J (2018) Potential effects of the combination of nicotinamide, vitamin B2 and vitamin C on oxidative-mediated hepatotoxicity induced by thioacetamide. Lipids Health Dis 17(1):29. https://doi.org/10.1186/s12944-018-0674-z

28. Popovic LM, Mitic NR, Miric D, Bisevac B, Miric M, Popovic B (2015) Influence of vitamin $C$ supplementation on oxidative stress and neutrophil inflammatory response in acute and regular exercise. Oxid Med Cell Longev 2015(295497):7 https://doi.org/10.1155/2015/295497

29. Kashif SM, Zaidi R, Tariq MA, Nasrul H, Naheed B (2003) Modulation of restraint stress induced oxidative changes in rats by antioxidant vitamins. J. Nutr. Biochem. 14:633-636

30. Ighodaro OM, Akinloye OA (2018) First line defence antioxidantssuperoxide dismutase (SOD), catalase (CAT) and glutathione peroxidase (GPX): Their fundamental role in the entire antioxidant defence grid. Alexandria J Med 54:287-293

31. Chu X, Zhou Y, Hu Z, Lou J, Song W, Li J et al (2016) 24-hour-restraint stress induces long-term depressive-like phenotypes in mice. Sci Rep 6:32935. https://doi.org/10.1038/srep32935

32. Olayaki LA, Sulaiman SO, Anoba NB (2015) Vitamin C prevents sleep deprivation-induced elevation in cortisol and lipid peroxidation in the rat plasma Niger. J Physiol Sci 30:005-009

33. Rai J, Pandey SW, Srivastava RK (2004) Chronic restraint stress cuased marked suppression of serum testosterone. J Anat Soc India 53:17-19

34. Damegh MA (2014) stress induced changes in testosterone secretion in male rats: role of oxidative stress and modulation by antioxidants. Open J An Sci 4:70-78

35. Orr TE, Mann DR (1992) Role of Glucocorticoids in the stress induced suppression of testicular steroidogenesis in adultmale rats. Hormone Behav 26:350-363
36. Jeong JY, Lee DH, Kang SS (2013) Effects of chronic restraint stress on body weight, food intake, and hypothalamic gene expressions in mice. Endocrinol Metab 28:288-296. https://doi.org/10.3803/EnM.2013.28.4.288

37. Bansal AK, Bilaspuri GS (2011) Impacts of oxidative stress and antioxidants on semen functions. Vet Med Int 2011(686137):7 https://doi.org/10.4061/ $2011 / 686137$

38. Vijayprasad S, Bb G, Bb N (2014) Effect of vitamin C on male fertility in rats subjected to forced swimming stress. J Clin Diagn Res 8(7):HC05-HC08. https://doi.org/10.7860/JCDR/2014/8432.4622. Epub 2014 Jul 20. PMID: 25177581; PMCID: PMC4149087

\section{Publisher's Note}

Springer Nature remains neutral with regard to jurisdictional claims in published maps and institutional affiliations.

\section{Submit your manuscript to a SpringerOpen ${ }^{\circ}$ journal and benefit from:}

- Convenient online submission

- Rigorous peer review

- Open access: articles freely available online

- High visibility within the field

- Retaining the copyright to your article

Submit your next manuscript at $\boldsymbol{\nabla}$ springeropen.com 